\title{
The Origin of Nanoscopic Grooving on Vesicle Walls in Submarine Basaltic Glass: Implications for Nanotechnology
}

\author{
Jason E. French and Karlis Muehlenbachs \\ Department of Earth and Atmospheric Sciences, University of Alberta, 1-26 Earth Science Building, \\ Edmonton, AB, Canada T6G 2E3 \\ Correspondence should be addressed to Jason E. French, jef@ualberta.ca
}

Received 20 December 2008; Revised 26 May 2009; Accepted 3 September 2009

Recommended by P. Panine

Dendritic networks of nanoscopic grooves measuring $50-75 \mathrm{~nm}$ wide by $<50 \mathrm{~nm}$ deep occur on the walls of vesicles in the glassy margins of mid-ocean ridge pillow basalts worldwide. Until now, their exact origin and significance have remained unclear. Here we document examples of such grooved patterns on vesicle walls in rocks from beneath the North Atlantic Ocean, and give a fluid mechanical explanation for how they formed. According to this model, individual nanogrooves represent frozen viscous fingers of magmatic fluid that were injected into a thin spheroidal shell of hot glass surrounding each vesicle. The driving mechanism for this process is provided by previous numerical predictions of tangential tensile stress around some vesicles in glassy rocks upon cooling through the glass transition. The self-assembling nature of the dendritic nanogrooves, their small size, and overall complexity in form, are interesting from the standpoint of exploring new applications in the field of nanotechnology. Replicating such structures in the laboratory would compete with state-of-the-art nanolithography techniques, both in terms of pattern complexity and size, which would be useful in the fabrication of a variety of grooved nanodevices. Dendritic nanogrooving in $\mathrm{SiO}_{2}$ glass might be employed in the manufacturing of integrated circuits.

Copyright ( $\odot 2009$ J. E. French and K. Muehlenbachs. This is an open access article distributed under the Creative Commons Attribution License, which permits unrestricted use, distribution, and reproduction in any medium, provided the original work is properly cited.

\section{Introduction}

Vesicles in the glassy margins of submarine pillow basalts can exhibit a range of internal features that collectively record information pertaining to eruption dynamics, deformational history, the composition of magmatic fluids linked with ore deposits of economic importance, and the explosive behaviour of some "popping rocks" upon dredging from the ocean floor [1-6]. Sulfide spherules commonly decorate vesicle interiors, in between which may also occur complex dendritic patterns of nanoscopic $(<100 \mathrm{~nm}$ wide) grooves that impart a polygonal or "turtleback" appearance to some vesicle walls $[3,5]$. The significance of these grooves is unclear, but it has been proposed that they might be an etching phenomenon [3] and that they resemble shrinkage cracks [5]. Evaluating their exact origin is important, because they could help elucidate a number of different geological processes, and they are similar in size and form to microbial trace fossils [7] and etch-tunnels [8] described from this geological environment.
Understanding these natural examples of nanoscopic grooving in glass may also lead to novel applications in the field of nanotechnology. Specifically, determining the physical process that leads to their formation could help to develop new methods of generating grooved patterns in synthetic materials that are useful in the fabrication of nanodevices. New technologies in sub-100 nm fine pattern formation are anticipated to replace traditional optical lithography techniques in the fabrication of integrated circuits [9], and one of the problems associated with state-of-the-art nanolithography techniques is the generation of complex patterns [10]. In seeking alternatives to nanolithography there is presently much focus on processes that are based on self-assembly, such as the myriad forms of self-assembly exhibited by biological systems [10]. From that standpoint, the complex dendritic nature of the nanogrooves makes determining their origin especially important.

In this paper, we describe and characterize dendritic patterns of nanogrooves that occur on the interior walls of vesicles from a glassy pillow margin from the North Atlantic 


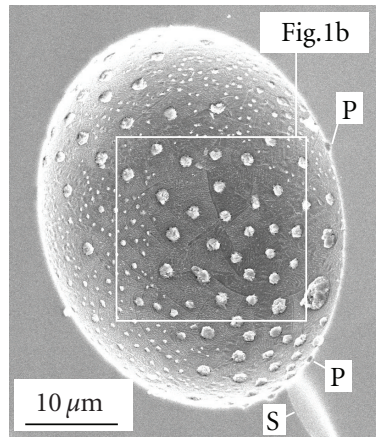

(a)

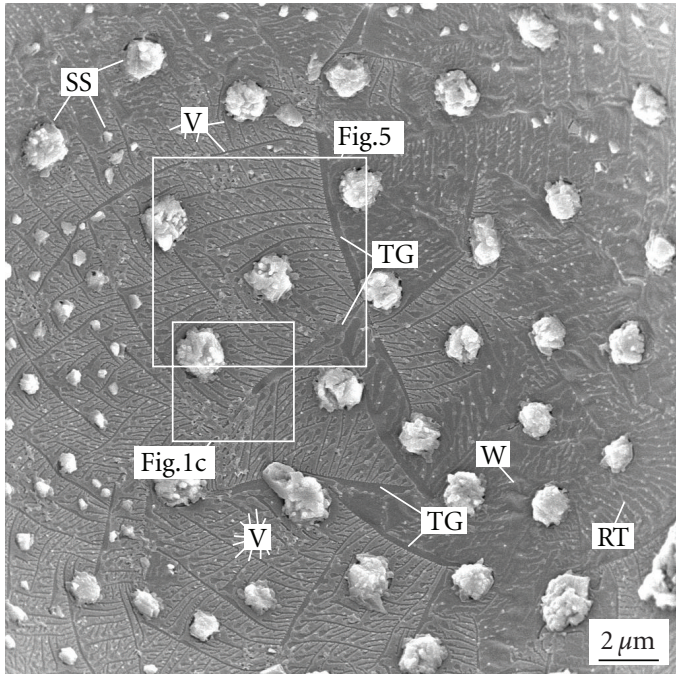

(b)

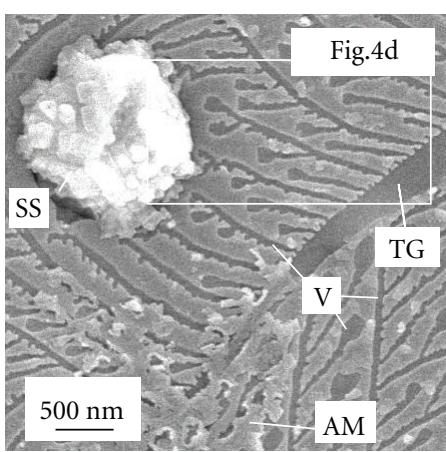

(c)

FIGURE 1: SEI images of a grooved vesicle from the glassy margin of a submarine pillow basalt from DSDP-418A-75-3-[120-123]. The sample is coated with $\sim 150 \AA$ of Au. (a) Overview of the vesicle. Note the step (S) in the fracture surface at lower right, which formed in lee of the vesicle as a propagating fracture opened it from upper left to lower right. Pits along the rim of the vesicle (P) show where sulfide spherules once were. (b) Close-up of the vesicle wall from (a) highlighting the distribution of sulfide spherules (SS) and dendritic patterns of nanoscopic grooves (viscous fingers- $\mathrm{V}$ ) on the vesicle wall, in addition to other less commonly observed textural features including tension gashes (TG), wrinkles (W), and rill and trellis texture (RT). (c) Detail from (b) showing a Cu-bearing iron sulfide spherule (SS), dendritic nanogrooves (viscous fingers-V), a tension gash (TG), and amorphous material (AM) that postdates and partially obscures the viscous fingers and the tension gash.

Ocean. The aim of this study is to determine the geological origin/meaning of the nanogrooves and to elucidate how they formed by comparison to known physical processes that lead to the formation of similar structures. In terms of their size and the morphological characteristics of their complex dendritic form, the relevance of these natural examples of nanogrooves in silicate glass to the field of nanotechnology is outlined.

\section{Sample Descriptions and Scanning Electron Microscopy}

Vesicle-bearing basaltic glass in this study originates from a sample of a glassy pillow margin from core sample 418A75-3-[120-123], collected from Deep Sea Drilling Project (DSDP) Hole 418A. The drill hole is situated under $5511 \mathrm{~m}$ of water in the North Atlantic Ocean at $25^{\circ} 02.10^{\prime} \mathrm{N}$ latitude and $68^{\circ} 03.44^{\prime} \mathrm{W}$ longitude, and the sample originates from $785 \mathrm{~m}$ below the seafloor, $461 \mathrm{~m}$ below the top of the volcanic basement [11]. Sand to pebble-sized basaltic glass fragments were isolated from a hand crushed sample of the glassy pillow margin. These fragments were then coated using a Nanotech Semprep2 with $\sim 150 \AA$ of gold (Figures 1(a)1 (c); 2(e)) or using a Xenosput XE200 with $\sim 10-15 \AA$ of chromium (Figures 2(a)-2(d)), for secondary electron imaging (SEI) with a JEOL 6301F field emission scanning electron microscope equipped with a PGT IMIX model Xray analysis system.
Vesicles are common and typically spherical to subspherical, $10-50 \mu \mathrm{m}$ in diameter, occasionally ranging in size up to $\sim 100 \mu \mathrm{m}$ in diameter. Most have smooth walls, which are embedded with numerous $\mathrm{Cu}$-bearing iron sulphide spherules of varying grain size, ranging from miniscule $(<200 \mathrm{~nm})$ to $>6 \mu \mathrm{m}$ across, although some vesicle walls are also ornamented by complex dendritic patterns of nanoscopic grooves (Figures 1 and 2).

2.1. Sulfide Spherules on Vesicle Walls. The vesicles of interest in this study are surrounded by fresh basaltic glass and have many $\mathrm{Cu}$-bearing iron sulfide grains decorating their interior walls (Figures 1 and 2). There is some debate as to whether such spherules originate from reaction of sulferous magmatic fluids with other elements diffusing into the vesicle from the host magma or from bubbles of magmatic fluids of complex composition that already contain all of the required elements dissolved within them [1]. In many cases it is clear that the sulfide grains formed along the bubble miniscus before quenching of the magma into glass, because the contacts between spherules and vesicle walls tend to form hemispherical pits $[1-3,5]$. Analogous pits along the rims of the vesicles (Figures 1(a) and 2(a)) reveal where sulfide spherules that have now been popped out were once partly embedded in magma.

In both vesicles, sulfide spherules show a range of grain sizes. One vesicle (A) has large populations of equant, $0.2-$ 0.5 and $1.0-1.5 \mu \mathrm{m}$ wide grains, in addition to a single 


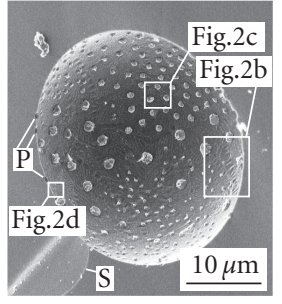

(a)

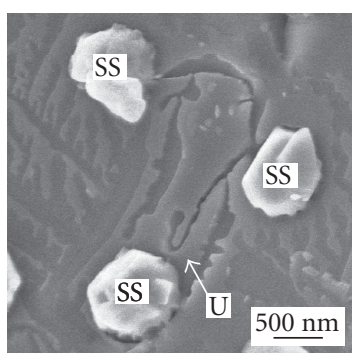

(c)

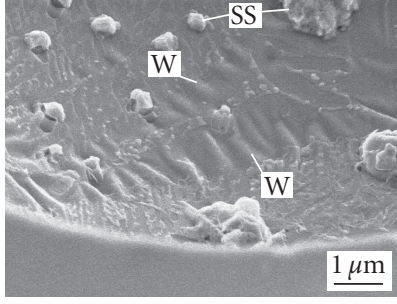

(b)

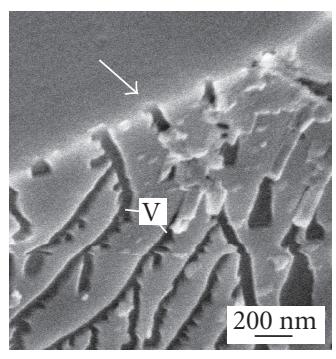

(d)

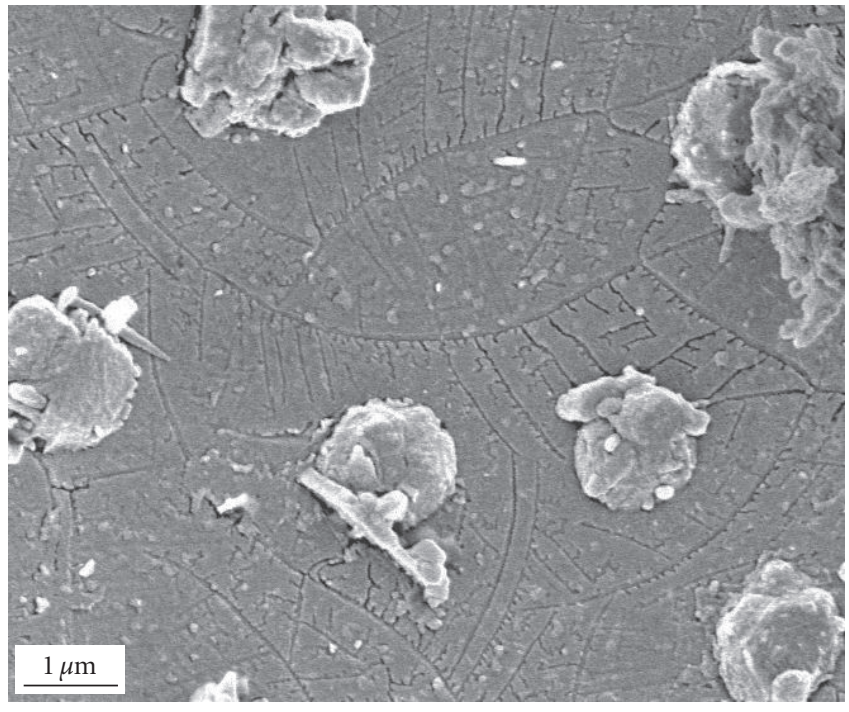

(e)

FIGURE 2: SEI images of other similar vesicles. The vesicle shown in (a)-(d) exhibits grooved features analogous to those shown in Figure 1, but is from a different glass fragment from the same pillow margin sample, and is coated with a $\sim 5-15 \AA$ thick layer of Cr. (a) Overview of the vesicle highlighting a step (S) in the fracture that exposed the vesicle, which formed in lee of it as the propagating fracture opened it from upper right to lower left, and pits (P) along the edge of the vesicle indicating where sulfide spherules once were. (b) Close-up of the vesicle from (a) showing numerous sulfide spherules (SS) and multiple elongate ribbon-like domains that exhibit a wrinkled surface texture (W). Such wrinkled, ribbon-like domains are interpreted as another form of pull-apart viscous deformation contemporaneous with viscous fingering and development of tension gashes (see Figure 7). (c) Close-up of the vesicle from (a) showing where a solitary viscous finger seems to have pulled a $180^{\circ} \mathrm{U}$-turn (U) before stopping and spreading out into a terminal bulb as it was shielded by a sulfide spherule (SS). Some faint, more lobate viscous fingers at left are interpreted to indicate shallowing of the boundary layer to perhaps $\sim 10 \mathrm{~nm}$ there. (d) Close-up of the vesicle from (a) showing where viscous fingers intersect the plane of the fracture that exposed their host vesicle, allowing for a precise estimate of finger depth at $\sim 50 \mathrm{~nm}$ (arrow). (e) Overview of a portion of a vesicle that is nearby ( $\sim 400 \mu \mathrm{m}$ away on the same fragment of glass) to that shown in Figure 1, exhibiting branching grooves of the same size, but with a slightly different form. In this case the nanoscopic grooves lack the distinctive terminal bulbs and lobate forms observed in the other two vesicles (Figures 1 and 2(a)-2(d)), and, instead of viscous fingers, are interpreted to represent brittle radial microfractures that formed in a thin boundary layer surrounding the vesicle. (Sample is coated with $\sim 150 \AA$ of $\mathrm{Au}$.)

larger oblate spheroidal grain that measures $\sim 4.0 \mu \mathrm{m}$ across (Figure 1(a)). The other vesicle (B) also has multiple, large populations of equant sulfide spherules that have distinctive grain sizes including $0.3-0.5,0.6-0.9$, and $1.2-$ $1.4 \mu \mathrm{m}$ (Figure 2(a)). For both vesicles, spherule spacing seems to be a function of grain size, with the average distance between grains increasing with average grain size (Figure 3(a)) (note that the effects of foreshortening due to the spheroidal shape of the vesicle wall were considered in these measurements). This relationship could be the result of interparticle (e.g., electrostatic) repulsive forces and possibly other external forces (e.g., fluid drag and surface tension) acting to repel grains about the meniscus at the time of glass quenching. The contrasting slopes for plots of average grain size versus average spacing of sulfide spherules in the two vesicles (Figure 3(a)) might then reflect differences in relative accommodation space linked with varying initial fluid compositions (i.e., varying sulfide-to-vesicle volume ratios). Previous studies of such sulfide spherules also documented a regular spacing between individual grains $[2,3]$, with the smallest spherules spaced far from, or at maximum distance from the larger ones $[1,3,5]$, and the largest spherules tending to depart from a spherical shape to a more flattened ellipsoid $[2,4]$.

Although the dataset is sparse (constrained by three data-points), the relationship observed for sulphide grain size versus sulphide spacing in vesicle B (Figures 2(a) and 3(b)) seems to also hint at a fractal distribution of sulphide spherules on the vesicle wall. This is because when solving for the fractal dimension $\left(d_{f}\right)$ using the generalized equation:

$$
d_{f}=\frac{\ln \left(N_{i+1} / N_{i}\right)}{\ln \left(R_{i} / R_{i+1}\right)},
$$

where for a given order, $N_{i}$ is the number of objects, and $R_{i}$ is the characteristic linear dimension [15], we find that $d_{f}$ is nearly identical in each case $(0.91,0.90$, and 0.89$)$, when calculating from the three possible paired sets of domains from the sulphide spacing/grain-size data (Figure 3(a)). We quantified the individual fractal dimension for each paired set of data, by equating the average sulphide spherule diameter with $R$ in (1), and considering $N$ as the total number of sulphides that plot in a large hypothetical flat plane (e.g., 1000 by $1000 \mu \mathrm{m}$ ) for each domain, which is in turn controlled by the average sulphide spacing (assuming 


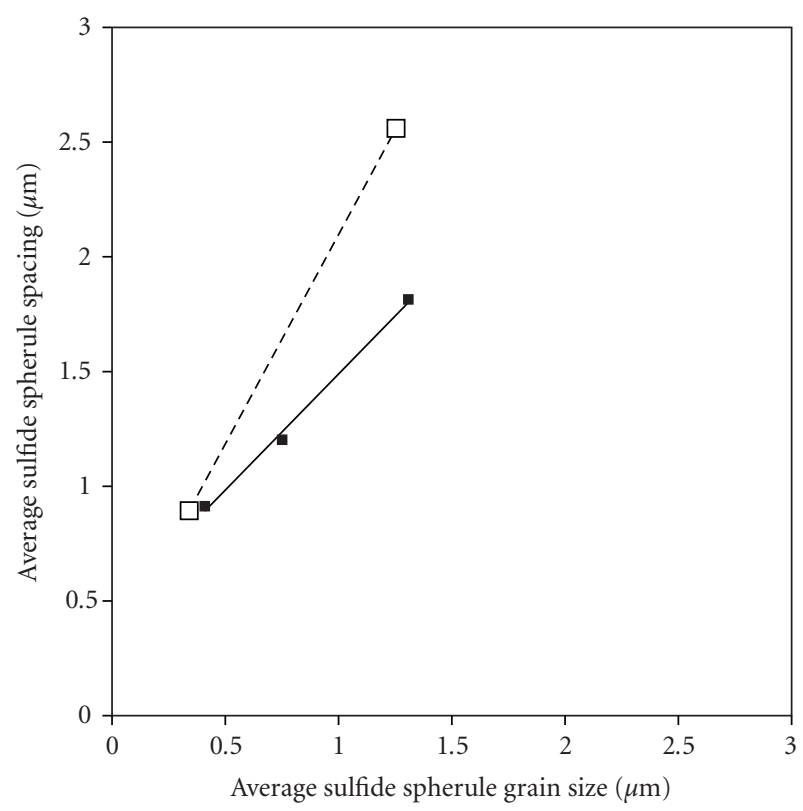

(a)

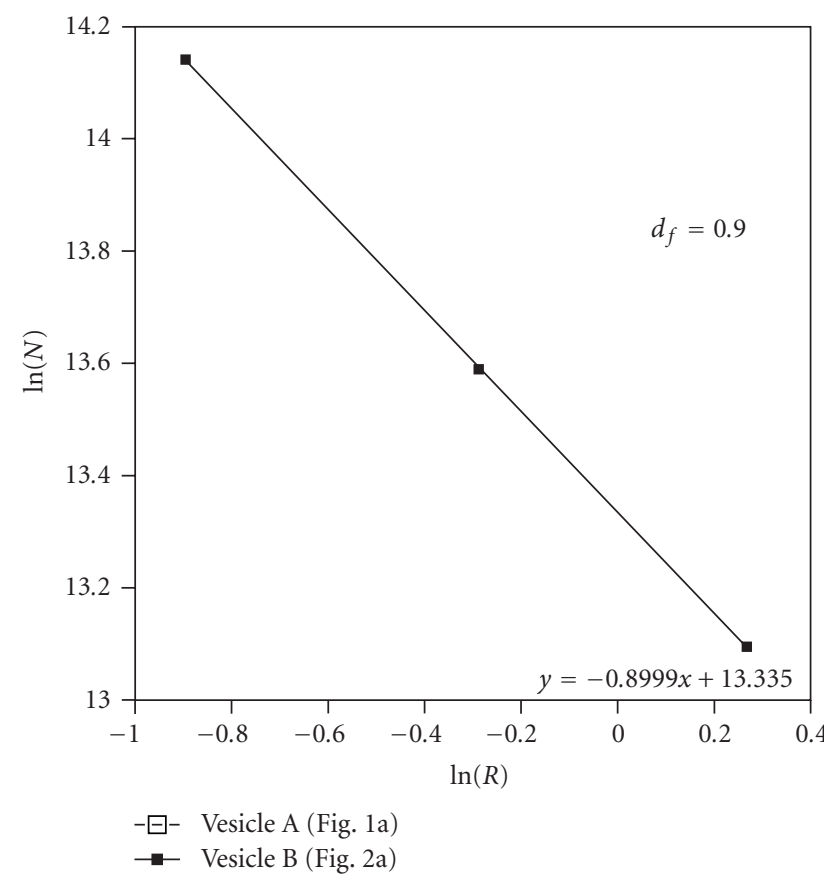

(b)

FIGURE 3: Grain size/spacing relationships of sulphide spherules on vesicle walls. (a) Plots of average grain size versus average spacing for five populations of sulfide spherules embedded in vesicle walls. (b) Determination of the fractal dimension $d_{f}$ for the pattern of sulphide spherules embedded in the wall of vesicle B (Figure 2(a)).

that the sulphides are arranged in hexagonal arrays). For $R=$ $0.409,0.751$, and $1.308 \mu \mathrm{m}$, average spacing is $0.913,1.203$, and $1.814 \mu \mathrm{m}$, respectively, with corresponding $N$ values of 1385246,797883 , and 486658 . Plotting $\ln (R)$ versus $\ln (N)$ for each scenario (Figure 3(b)) also yields a composite regression line that has a slope equal to the fractal dimension (multiplied by -1 ), corresponding to a value of 0.90 for $d_{f}$ (Figure 3(b)). The significance of this apparently fractal distribution of sulphide spherules is unknown, although it may relate to a fractal distribution of trace element concentrations in the vesicle at the time of their formation akin to that observed for some ore deposits [16], or a consequence of other combined forces acting to distribute the grains about the meniscus before glass quenching (e.g., electrostatic, fluid drag).

2.2. Nanogrooves on Vesicle Walls. In between the sulfide spherules are elaborate patterns of shallow $(\sim 50 \mathrm{~nm})$, branching grooves that are reminiscent of the dendritic pattern produced by the veins in a plant leaf (Figures 1(b) and $1(\mathrm{c}))$. The grooves occur in arcuate, subparallel sets that are spaced regularly and branch at locally constant angles ranging from $\sim 30-90^{\circ}$ (typically $40-60^{\circ}$ ). Subsidiary branch-sets tend to be shorter in length (although not in every case) and invariably branch off to only one preferred side of the previous parent set of grooves. Individual grooves are typically $50-75 \mathrm{~nm}$ wide and branch-tips typically occur as bulbous terminations that measure $150-300 \mathrm{~nm}$ across. In vesicle $A$, many of the trees seem to be rooted in wider arcuate grooves or lenses that are up to $0.5 \mu \mathrm{m}$ wide at the center and which pinch out at the ends. Locally these grooves are postdated by thin films of amorphous material of unknown composition, which partially blankets and obscures them (Figure 1(c)). On the right side of the vesicle, branching grooves are rare, and the area seems to be dominated by wrinkled surfaces and regions showing a distinctive rill and trellis texture (Figure 1(b)). Though Fe sulfide spherules are almost ubiquitous in vesicles from the basaltic glass pillow margin studied, only a few $\%$ of all vesicles have grooved walls such as this (Figure 1), with most walls being smooth and featureless between sulfide spherules.

\section{Origin of Dendritic Nanogrooves on Vesicle Walls}

The vesicle in Figure 1 has many branching grooves that form a large number of interrelated tree-like patterns, which collectively span a large part of the total surface area of the vesicle wall (Figure 1(b)). Interrelationships between trees, the fine details of their appearance, and the continuity in the overall pattern have been used to place additional constraints on the origin of these grooves, through comparisons to relevant physical processes that lead to the formation of similar dendritic structures. An incredible diversity of natural growth phenomena generates dendritic patterns, many of which are scale-invariant or fractal and may be modelled by diffusion-limited aggregation [17], and these include dendritic crystals [18], vascular systems in plants and animals [19], drainage networks [20], and viscous fingering [21] to name a few.

Studies in viscous fingering involve characterizing the patterns of displacement of a viscous fluid by a relatively less viscous invading fluid, injected into it within the narrow space between two parallel transparent plates known as a 


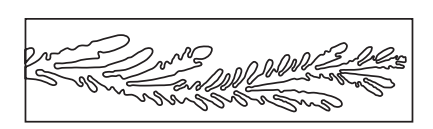

(Modified from [12]-Arenéodo et al., 1989)

(a)

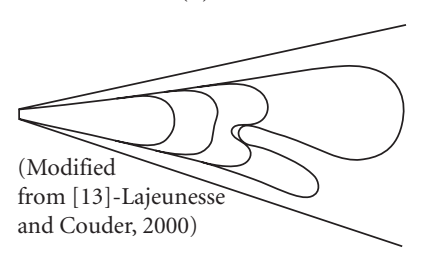

(b)

(Modified from [14]- Liang, 1986)

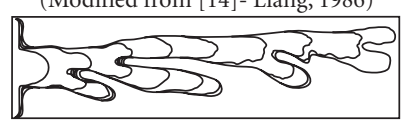

(c)

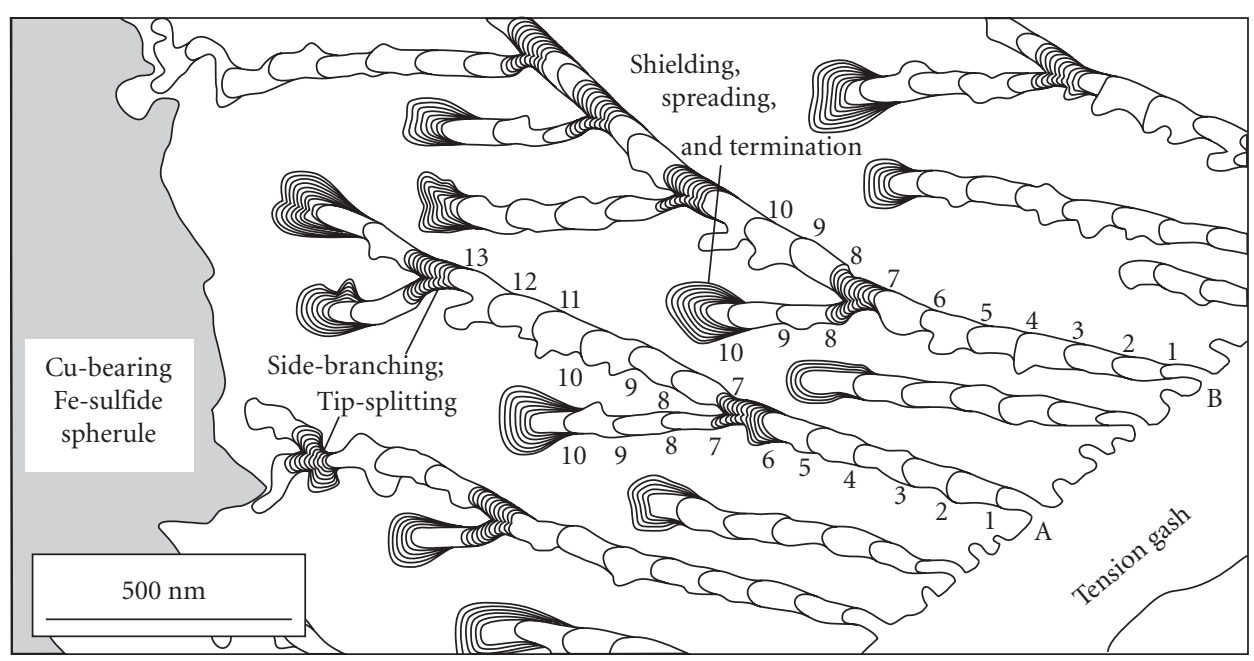

(d)

FIGURE 4: Interpretation of branching nanogrooves as viscous fingering trees. (a) Drawing traced from a photograph [12] of a very unstable viscous finger of air injected into silicon oil, within a linear Hele-Shaw cell of $10 \mathrm{~cm}$ width and $0.25 \mathrm{~mm}$ thickness. (b) Drawing traced from a composite image of four photographs [13] of viscous fingers at four different stages of growth, formed by air injected into silicon oil within a sector-shaped Hele-Shaw cell of angle $30^{\circ}$. (c) Drawing traced from a computer generated image [14] showing multiple growth stages of simulated viscous fingers that were produced using an algorithm related to diffusion-limited aggregation. (d) Drawing traced from a closeup view from Figure 1(c) showing $100 \mathrm{~nm}$ incremental growth of viscous fingers (numbers), and additional $10 \mathrm{~nm}$ incremental growth for all tip-splitting (side-branching) and spreading events, assuming that all viscous fingering trees started to grow simultaneously at constant rates. Examining this growth model in forward motion: finger A undergoes a tip-splitting (side-branching) event at around $\sim 650 \mathrm{~nm}$, as does finger B at around $\sim 750 \mathrm{~nm}$. The new side-branch produced by finger B stops growing and spreads out into a terminal bulb at around $1050 \mathrm{~nm}$ of growth, because finger A has already passed through the region that it is approaching, effectively shielding it from further growth. At $\sim 1300 \mathrm{~nm}$, finger A undergoes a final tip-splitting event, after which the main finger in addition to the new side-branch both stop growing and spread into terminal bulbs as they are shielded from further growth by the sulfide spherule.

Hele-Shaw cell [22]. Intricate patterns of branching viscous fingers of the invading fluid may develop as instabilities at the interface between the fluids arise and evolve [21, 23]. Typically, the mechanism of the instability is intimately linked with viscosity variations between the fluid phases, and this is why the term "viscous fingering" is commonly used [21]. As they are classically studied within the narrow gap between parallel transparent plates, images of viscous fingers are represented as quasi-two-dimensional curvilinear boundaries or traces of the interface between the two fluids $[21,24]$, that for complex patterns outlines the form of a highly branched dendritic structure (Figures $4(\mathrm{a})-4(\mathrm{c})$ ). The complexity of viscous fingering trees is controlled mainly by three pattern forming processes that can be summarized as tip-splitting, shielding, and spreading [21, 24].

Comparison of the patterns of nanoscopic branching grooves on the vesicle wall in this study to dendritic viscous fingering patterns reveals many similarities. In detail, the outline of the grooves forms a continuous curvilinear trace that is reminiscent of the rounded curvilinear traces formed by branching viscous fingers in macroscopic experiments [24] and numerical simulations (Figures 4(a)-4(c)). Considering nearby individual trees to represent viscous fingers that started to grow simultaneously at identical rates, forward modelling shows that the patterns produced can be described in terms of tip-splitting (side-branching), shielding, and spreading (Figure $4(\mathrm{~d})$ ).
Two relatively long viscous fingers (fingers $\mathrm{C}$ and D in Figure 5) originating from two distal points seem to have arrived at the same location (star in Figure 5) at the same time and engaged in a competition to keep growing, mutually changing course in doing so. This observation was used to constrain a flat, best-fit growth model of viscous fingers across a relatively large portion of the vesicle wall where the effects of foreshortening (maximum $<2.5 \%$ cumulative) could be neglected (Figure 5). Colours show the time-dependent development of the viscous fingering trees, assuming that finger velocities are constant as they increase in length, but decelerate by $\sim$ half as they spread out into terminal bulbs and then stop. This assumption is consistent with experimental viscous fingering results, which show that tip velocity is constant at constant flow rate, even during tipsplitting events and shielding of other fingers that slow to a stop [24]. One measure of the reliability of the resulting growth model is an examination of how many viscous fingers were shielded in the proper sequence of events. For most of the pattern this seems to have worked (Figure 5), but more dynamic computer models with a range of different assumptions will be required to resolve a more accurate picture.

As the sulfide spherules on the vesicle wall were in place before viscous fingering began, many of them, regardless of their size, appear to have acted as obstacles that shielded viscous fingers from further growth, if the propagating tips 


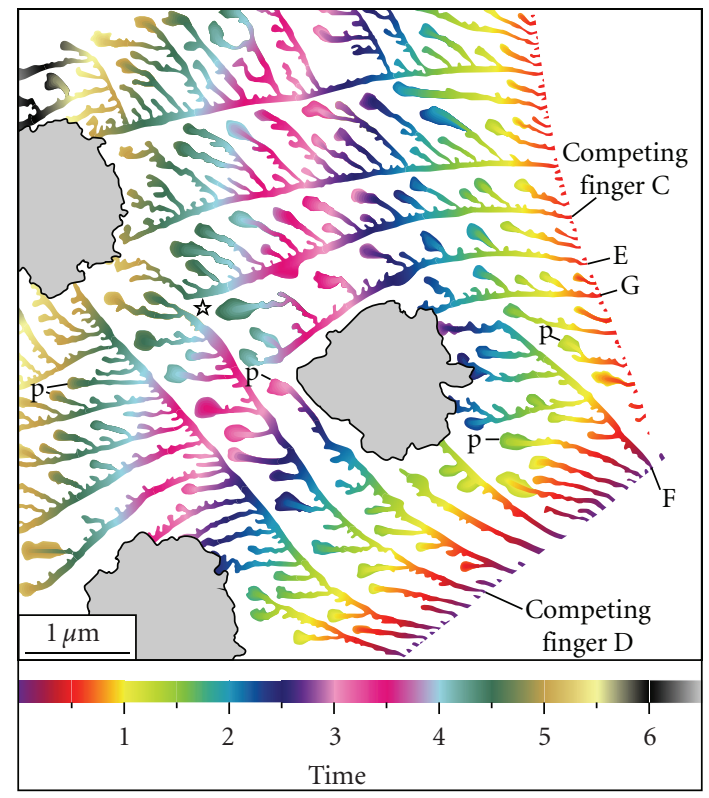

FIGURE 5: Modelling the propagation of viscous fingering trees across the central portion of the vesicle wall from Figure 1(b). In this computer-aided interpretive drawing of dynamic viscous fingering, the colours show the time-dependent development of the branching viscous fingers according to a realistic growth model. Specifically, colours were assigned by assuming that finger velocities are constant as they increase in length but decelerate by $\sim$ half as they spread out into terminal bulbs and then stop. This assumption is consistent with experimental results for macroscopic viscous fingering, which show that tip velocity is constant at constant flow rate, even during tip-splitting events and shielding of other fingers that slow to a stop [24]. In this growth model, it is also assumed that all neighbouring viscous fingers originating from the same tension gash started growing at the same time (see an explanation of this process in Section 3.2). Based on morphology, viscous fingers $\mathrm{C}$ and $\mathrm{D}$ are interpreted to have arrived at the same location at the same time (indicated on the figure with a star symbol) and consequently undergone a competition to outgrow one another in that region. This indicates that viscous fingers originating from both tension gashes were growing at the same time, constraining a delay of $\sim 0.5 \mu \mathrm{m}$ of growth time from one tension gash to the other as shown in the figure (i.e., competing finger $\mathrm{D}$ is $\sim 0.5 \mu \mathrm{m}$ longer than $\mathrm{C}$ when measuring back from the star). Examining the colours of neighbouring fingers where shielding events occur is one measure of the reliability of the resulting growth model. For instance, the colour of the very end of finger E shows that according to this model, it was properly shielded by finger D because it arrived approximately $1 \mu \mathrm{m}$ of growth time after finger D had passed in front of it. Similarly, finger $F$ was shielded by finger $G$ in the right sequence. Some fingers seem to have been shielded prematurely however (denoted by "p"), in that their tips slowed and stopped growing before the shielding finger had already arrived. Three $\sim 1.5 \mu \mathrm{m}$ wide $\mathrm{Cu}$-bearing $\mathrm{Fe}$ sulfide spherules are also shown (grey), which acted as obstacles that shielded viscous fingers. Note that this drawing was made using higher resolution SEI images of the area highlighted in Figure 1(b), which are not shown.

approached within $\sim 100-200 \mathrm{~nm}$ (Figure 4(d)). In one such shielding event, a viscous finger from another vesicle with analogous features seems to have pulled a complete $180^{\circ}$ U-turn before stopping and spreading out into a terminal bulb (Figure 2(c)). The observation that sulphide spherules affected the growth patterns of propagating viscous fingers in these ways is important, because it demonstrates that the viscous fingers formed after the sulphide spherules were already in place, providing support for the model that they date to the time of pillow eruption (quenching). It is also interesting from the standpoint of understanding pattern formation during viscous fingering in general, especially because the sulphides not only caused shielding events to occur at a distance of $\sim 100-200 \mathrm{~nm}$ but also caused deflection of viscous fingers to occur from a similar distance. To our knowledge, this phenomenon has not been described from classical macroscopic viscous fingering experiments - that is, the mechanisms that control the growth and pattern formation during viscous fingering are classically summarized as tip-splitting, shielding, and spreading [21,24]. Deflection, or perhaps more effectively, steering, or redirection of viscous fingers by nearby objects, is included as another mechanism affecting pattern formation during viscous fingering in this geological environment. This also raises a question as to why sulphide spherules caused shielding events to occur in most cases and deflection/redirection in at least one isolated instance (Figure 2(c)).

Viscous fingers from that vesicle (Figures $2(\mathrm{a})-2(\mathrm{~d})$ ) are for the most part identical in width $(\sim 50-75 \mathrm{~nm})$ to those from the other vesicle (Figure 1(c)) and to grooves reported from vesicles in the Nazca plate $[3,5]$. Where they intersect the fracture that exposed their host vesicle, they allow for measurement of their depth at $\sim 50 \mathrm{~nm}$ (Figure 2(d)), which is interpreted to correspond to the thickness of the dehydrated boundary layer that contains them.

\subsection{Quantitative Scaling Analysis of Dendritic Nanogrooves.} The complex dendritic patterns commonly observed in macroscopic experiments and numerical simulations of viscous fingering can also be characterized quantitatively using the fractal approach $[25,27]$. Because fractal structures are scale invariant, this allows for another method of comparing the nanoscopic viscous fingering patterns observed in this study with more classic macroscopic (cm-scale) examples.

In the experiments and numerical simulations of [25], the viscous fingering patterns produced exhibited a complex dendritic form with notably skeletal structures (i.e., narrow branches) that are similar in form to those observed here at a much smaller scale ( $\sim$ six orders of magnitude smaller). Consequently, in this scaling analysis of natural nanoscopic viscous fingers, we have determined the fractal dimension $\left(d_{f}\right)$ of the dendritic viscous fingering patterns by the method of [25] to allow a direct comparison to the patterns observed in their study.

Scaling analysis was carried out on a representative region of the dendritic nanogrooves observed on the wall of vesicle A (Figures 1, 5, and 6). This region (Figure 6(a)) was selected because it is flat and exhibits a significantly large viscous fingering tree that grew from a single source finger in an unconstrained fashion (i.e., was not affected by the 


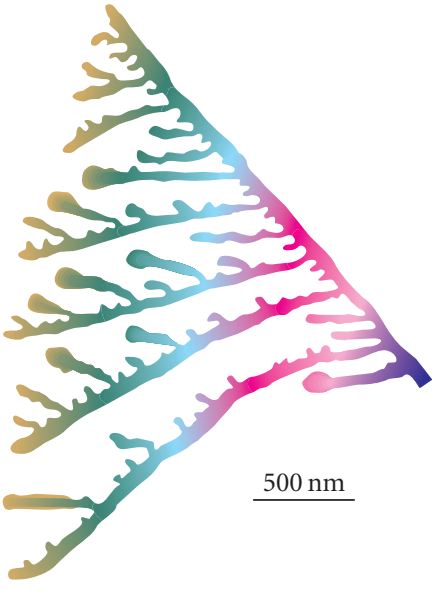

(a)

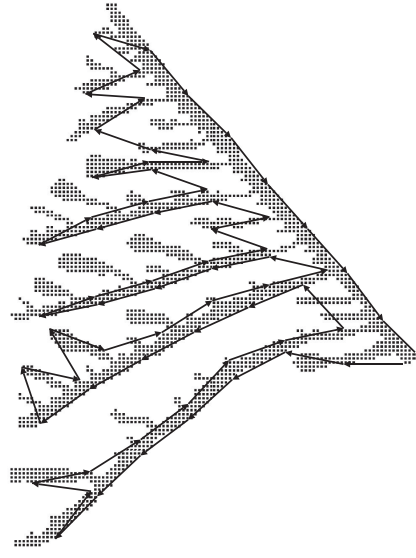

(b)

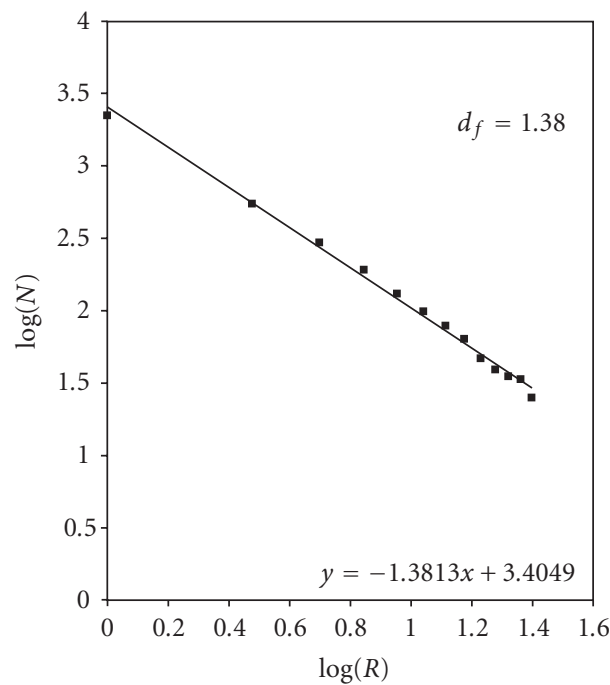

(c)

FIGURE 6: Quantitative scaling analysis of a representative region of dendritic nanogrooves (viscous fingering tree). (a) Overview of the selected region of dendritic nanogrooves, isolated from one of the viscous fingering trees in the growth modelling study of Figure 5. This region was selected as representative because it occurs in a flat region near the center of the vesicle and shows development of a significantly large region of dendritic nanogrooves that were not affected by nearby sulphide spherules or neighbouring starting viscous fingers during pattern formation. The size of the tree was also constrained by the growth model in Figure 5 (i.e., this portion of the tree comprises a total of $2.5 \mu \mathrm{m}$ of growth starting from the selected region of the primary stem-colours are the same as for Figure 5). (b) Pixelated image of the viscous fingering tree shown in (a). This image was used to determine the fractal dimension of the viscous fingering trees (dendritic nanogrooves) observed in this study. The method used to determine the fractal dimension is after [25], which involves measuring the apparent length of the perimeter of the pixelated image numerous times systematically with a ruler of increasing length (from one pixel to 25 pixels in length). Determination of the apparent length of the perimeter with a ruler of 15 pixels in length is shown to illustrate how these measurements were made. (c) Determination of the fractal dimension $\left(d_{f}\right)$ from the apparent length measurements of the perimeter $(N=$ apparent length in units of $R ; R=$ length of the ruler in pixels).

presence of sulphide spherules or adjacent parallel starting fingers). Growth modelling (Figure 5) was used to constrain the size of the tree, by assuming exactly $2.5 \mu \mathrm{m}$ of growth from a single starting point on the primary stem. In this manner, a representative portion of a single, unconstrained viscous fingering tree (Figure 6(a)) was isolated from a larger structure (Figure 5).

Measurement of the fractal dimension $\left(d_{f}\right)$ was done after the method of [25]. This involved pixelating the selected viscous fingering pattern and then measuring the apparent length $(N)$ of the perimeter numerous times systematically, with successively larger rulers of increasing length $R$ that ranged from 1 pixel to 25 pixels in length (Figure 6(b)). If the structure is fractal, then the apparent length should decrease as $R^{-d_{f}}$ [25], and in the present study on the selected region of branching nanoscopic viscous fingers we observed this relationship to be true (Figure 6(c)). On a plot of $\log (R)$ versus $\log (N)$, the slope of the regression line through the data (multiplied by -1 ) is equal to the fractal dimension [25], which we determined in this case to be 1.38 (Figure $6(\mathrm{c})$ ). This value is identical to that determined (1.38) for viscous fingering of water injected into a polymer solution in a Hele-Shaw cell [25]. This remarkable similarity indicates that even at length scales six orders of magnitude smaller, and with a very different suite of fluids (magmatic vapour injected into hot basaltic glass), the viscous fingering phenomenon yields an identical fractal structure. This supports the notion of [25], that viscous fingering yields a universal value for $d_{f}$ for a wide range of fluid compositions and viscosity contrasts. Ultimately, a value of $d_{f}$ determined on nanogrooves in this study (1.38) that is identical to macroscopic viscous fingering experiments provides additional quantitative evidence to support the idea that these naturally occurring nanogrooves are in fact exceptionally tiny viscous fingers.

3.2. Summary of the Model. There is enough information within the interrelated dendritic patterns of grooves on the vesicle wall in Figure 1 to conclude that they represent viscous fingering trees. The grooves themselves represent fingers of very low-viscosity $\left(\sim 4 \cdot 10^{-5} \mathrm{~Pa} \cdot \mathrm{s}\right.$ for $\mathrm{CO}_{2}$ vapour at $30 \mathrm{MPa}$ and $600-700^{\circ} \mathrm{C}$ [28]) magmatic fluid that were injected into a shell-like boundary layer of hot $(\sim 600-$ $700^{\circ} \mathrm{C}$ across the glass transition for basalt [29]) dehydrating basaltic glass with much higher relative viscosity $\left(\sim 10^{9}\right.$ to $\sim 10^{11} \mathrm{~Pa} \cdot \mathrm{s}$ across the glass transition for basalt [29]) that seems to have acted as a $\sim 50 \mathrm{~nm}$ thick, natural example of a Hele-Shaw cell. The magmatic fluid was likely dominated by $\mathrm{CO}_{2}$ vapour [30] and probably equilibrated with the ambient hydrostatic pressure $(\sim 30 \mathrm{MPa})$ in the time it took for the glassy pillow margin to form [31]. 


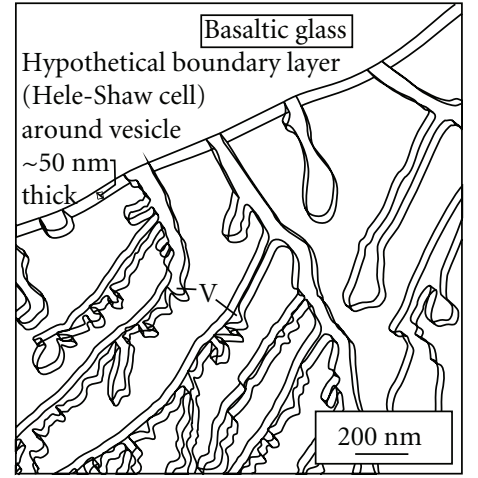

(a)

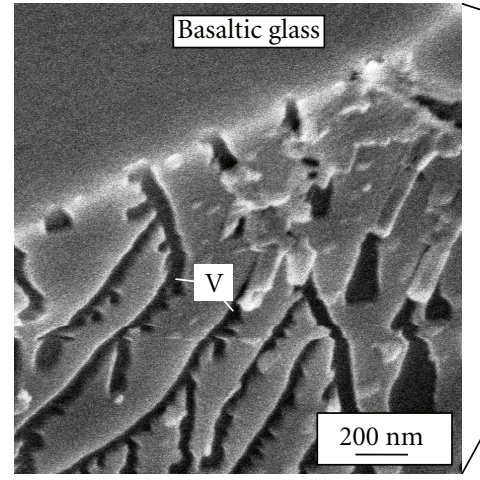

(b)

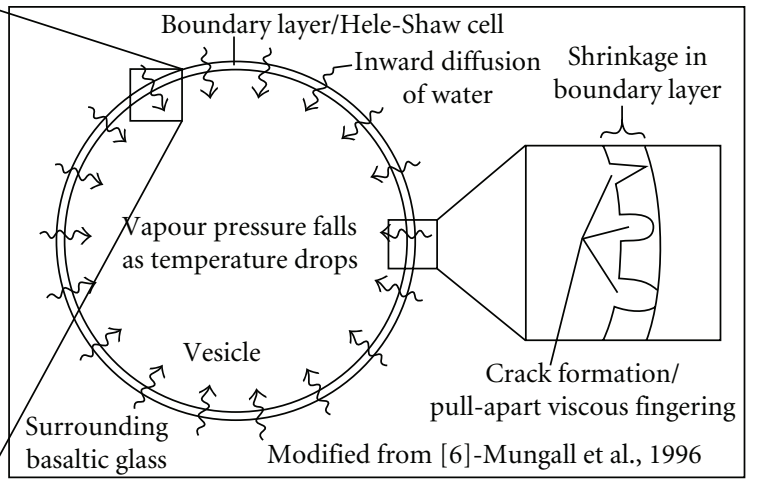

(c)

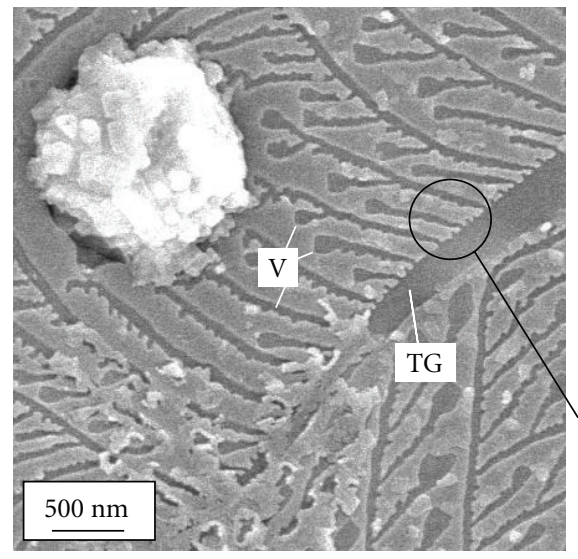

(d) i) Tangential tensile stress causes initial radial pull-apart viscous fingers to form within the boundary layer:

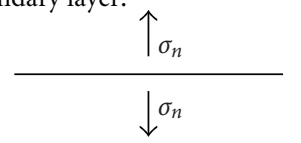

ii) Warping and opening of these initial viscous fingers into wider tension gashes.

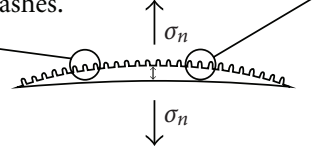

-iii) Extension on the convex out side of tension gashes provides focal points for starting viscous fingers of the next order.

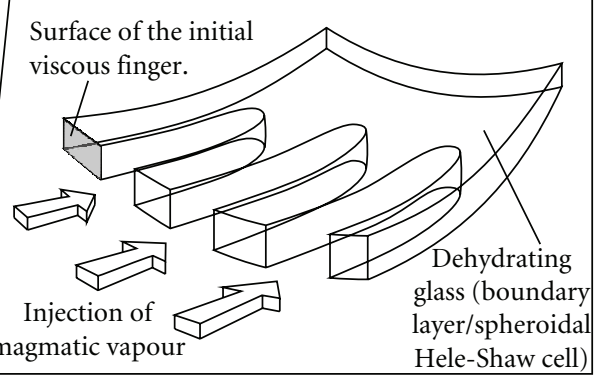

(e)

FIGURE 7: Summary diagram showing the conceptual model explaining the initiation and formation of nanoscopic viscous fingering patterns on vesicle walls in mid-ocean ridge basaltic glass. (a) Schematic illustration depicting a putative $\sim 50$ nm thick boundary layer around vesicle $\mathrm{B}$, corresponding to the possible configuration of a previously existing, natural Hele-Shaw cell, which now contains frozen (or fossil) viscous fingers $(\mathrm{V})$ of magmatic vapour. The thickness of this hypothetical boundary layer $(\sim 50 \mathrm{~nm})$ is estimated from the apparent depth of the fossil viscous fingers shown in (b). Although empirical evidence for the boundary layer has not yet been determined, it is predicted to comprise basaltic glass with slightly lower water contents than ambient values in surrounding glass. Note that in this example of ultrathin film surface layer viscous fingering on the vesicle wall, the Hele-Shaw cell essentially had imaginary walls, corresponding to the inner and outer reaches of the hypothetical dehydrated boundary layer. During viscous fingering, the more viscous fluid comprised hot basaltic glass that was probably near the glass transition temperature $\left(600-700^{\circ} \mathrm{C}\right)$ - the less viscous invading fluid being magmatic vapour that was probably dominated by $\mathrm{CO}_{2}$. (b) Close-up SEI image (from Figure 2) showing the region of vesicle B for which a hypothetical boundary layer is illustrated in (a) (V-viscous fingers). (c) Illustration of pull-apart nanofracturing/fracturing/viscous fingering in a thin boundary layer predicted by numerical modelling of stress generation around some vesicles in glassy rocks (modified from [6]). The SEI image from (b) is located on this conceptual model. (d) Close-up SEI image of a portion of the vesicle wall from Figure 1, linking a tension gash (TG), and viscous fingers (V) to the conceptual model of their formation shown in (e). (e) Model for the stepwise initiation of viscous fingering in a $\sim 50 \mathrm{~nm}$ thick boundary layer of glass around a vesicle in a glassy pillow margin. $\sigma_{n}$ denotes the components of traction normal to a surface, which define a tensile surface stress [26] that leads in this interpretation to the formation of a pull-apart viscous finger.

Similar, leaf-like patterns of nanoscopic branching grooves on vesicle walls in mid-ocean ridge basaltic (MORB) glass have also been recognized from DSDP site 320 in the Nazca plate $[3,5]$. They have been likened to shrinkage cracks [5], which is significant because numerical modelling studies actually predict the formation of microfractures generated by elastic shrinkage on the walls of some vesicles in glassy rocks, including submarine pillow lavas [6]. According to this conceptual model (Figure 7(c)), when the glass transition is reached during cooling, the gases trapped in the vesicle become constrained to an isochore because the vesicle can no longer shrink by viscous relaxation of the surrounding melt [6]. As a consequence, the chemical potential of water vapour in the vesicle falls out of equilibrium with the chemical potential of water in the glass, causing water to diffuse into the vesicle from a thin boundary layer of surrounding glass [6]. Elastic shrinkage in this boundary layer occurs because the density of hydrous basaltic glass is less than that of anhydrous basaltic glass, and the resulting strain generates tangential tensile stress that causes microfractures to form in a radial array around the vesicle (Figure $7(\mathrm{c})$ ). Branching nanogrooves on vesicle walls in this study are interpreted 
to represent similar pull-apart structures that formed in an analogous dehydrating boundary layer surrounding each vesicle (Figure 7).

The mechanism for generating tangential tensile stress around the vesicle during deformation is interpreted to have been the same as that proposed for generating radial microfractures around vesicles in glassy rocks [6] (Figure $7(\mathrm{c})$ ). In this case, however, deformation in the boundary layer is interpreted to have been viscous as opposed to brittle microfracturing (Figure 7). The deformation was initiated by generation of pull-apart viscous fingers that evolved into arcuate tension gashes (Figures $7(\mathrm{~d})$ and $7(\mathrm{e})$ ). Extension on the convex-out side of the tension gashes appears to have served as a focus for the onset of continued viscous fingering (Figures $7(\mathrm{~d})$ and $7(\mathrm{e})$ ).

A different type of nanoscopic grooves observed in another vesicle (Figure 2(e)) from DSDP 418A-75-3-[120123] provides additional evidence for invoking this numerical model [6] in determining the driving mechanism for viscous fingering. In this case, the branching grooves are identical in width and dendritic nature, but they do not have terminal bulbs and irregular lobate forms (as in Figures 1 and 2(a) $-2(d))$. For that reason, these nanogrooves (Figure 2(e)) are interpreted instead to represent brittle deformation in the form of shallow radial microfractures, akin to those predicted by the numerical simulations [6]. The occurrence of both types of deformation in the same pillow margin may reflect the crossover from viscoelastic fracture to viscous fingering with increasing water content that is known for some geological materials [32]. Regardless, both types of deformation are interpreted to have formed as a result of the same process (Figure 7), and they result in the formation of branching grooves of similar thickness and depth surrounding the vesicles. A comprehensive summary of this conceptual model is presented in Figure 7.

The observation that vesicles with grooved walls occur locally in this pillow margin sample amongst a larger population of vesicles with smooth, featureless walls, can be explained by differences in fluid composition between vesicles. Typically, vesicles in the glassy margins of submarine pillow lavas contain predominantly $(>95 \%) \mathrm{CO}_{2}$ as the vapour phase, with the remaining $~ 5 \%$ comprising mostly $\mathrm{H}_{2} \mathrm{O}$, in addition to other trace gases $[4,33]$. Of interest here is that volatile concentrations in vesicles from basaltic glasses from the mid-Atlantic ridge are known to vary at the vesicle-to-vesicle scale in the same glassy pillow margin [31], and variations in the $\mathrm{H}_{2} \mathrm{O}$ content of vesicles have also been observed in repeat measurements on glasses from the East Pacific Rise [4]. Variations in the original $\mathrm{H}_{2} \mathrm{O}$ content from vesicle-to-vesicle should influence the degree to which dehydration (leading to nanogrooving) will occur in the surrounding glass. This is because, in the numerical modelling studies of microfracturing around vesicles in glassy rocks, the decreasing vapour pressure inside the vesicle during cooling is compensated as water is added to it from the dehydrating boundary layer [6]. Intuitively, any excess water originally present in anomalously $\mathrm{H}_{2} \mathrm{O}$-rich vesicles (i.e., above equilibrium values with the surrounding glass) would result in increased starting partial vapour pressure of $\mathrm{H}_{2} \mathrm{O}$ in the vesicle, which would, in turn, decrease the amount of water entering the vesicle through dehydration of the surrounding glass, ultimately reducing the chances of microfracturing.

An alternative explanation for the occurrence of both grooved and smooth-walled vesicles in the same pillow margin is that the original water content in the glass itself might not have been perfectly homogeneous at the vesicleto-vesicle scale in the pillow margin. For instance, vesicles originally at equilibrium with surrounding glass will undergo microfracturing at higher temperature and vapour pressure if the water content in the surrounding glasses is higher (e.g., at $500 \mathrm{~K}$ for $\sim 1 \%$ and $600 \mathrm{~K}$ for $\sim 2 \%$ ) whereas vesicles surrounded by glass with lower water contents $(<0.4 \%)$ are not predicted to undergo microfracturing at all [6]. This explanation seems more likely, because it also provides an explanation for the two contrasting styles of nanogrooving observed in this study. In particular, nanoscopic grooves around the vesicle shown in Figure 1 are the result of hightemperature viscous fingering, while the nanogrooves in a vesicle that occurs only $\sim 400 \mu \mathrm{m}$ away (Figure 2(e)) seem to have formed by brittle microfracturing at presumably lower temperature. Differences in the initial water content in the glass surrounding each of these two vesicles would have triggered deformation around each vesicle at a different temperature in each case during cooling, and therefore at different times assuming identical cooling rates for the two vesicles. This could have resulted in early viscous deformation (at high temperature) around one vesicle, and late brittle microfracturing (at low temperature) around the other. According to this model, it is inferred that water contents in the glass were highest the surrounding vesicles that show nanoscopic viscous fingering, lower around vesicles exhibiting shallow brittle microfracturing, and the lowest around the most common type of smooth-walled vesicles (i.e., those where deformation of vesicle walls simply did not ensue).

\section{Discussion}

4.1. Implications for Geology. Branching nanoscopic grooves on vesicle walls in the glassy margins of mid-ocean ridge pillow basalts have now been described from the oceanic crust beneath the Pacific [3,5] and Atlantic Oceans (this study) and are therefore predicted to be globally widespread in the oceanic crust. Their existence may now be explained by invoking the fluid mechanical process of viscous fingering, which took place at a submicroscopic scale in these rocks. Individual nanogrooves represent viscous fingers of magmatic fluid that were frozen into place after being injected into a thin $(\sim 50 \mathrm{~nm})$ boundary layer of hot, dehydrating basaltic glass. Although they are not exactly microfractures, the grooves are linked with numerical predictions of microfracturing caused by elastic shrinkage during dehydration of some vesicle walls upon cooling through the glass transition [6]. 
Tubular dendritic microchannels are a common occurrence at the glass-palagonite alteration front in the glassy margins of mid-ocean ridge pillow basalts [7]. They are often interpreted as evidence for microbial etching [7] and in one recent study on the same rocks as the present study have been explained in terms of abiotic, preferential etchtunnelling along radiation damaged regions in the glass [8]. Branching microchannels attributed to microbial activity have actually been described from the same drill hole as rocks from the present study, and as having diameters as small as a few hundred nanometers (i.e., sample DSDP-418A62-4-[64-70]) [7], and these might also be reinterpreted in an nonbiological context [8]. Of importance here is that some of them (see [7, Figure 5]) also happen to be rooted along vesicle walls, extending outwards into fresh glass for $>100 \mu \mathrm{m}$, and therefore the geological setting of these features [7] overlaps with that for the branching nanoscopic channels described here. Because of the similarities in size and overlap in geological setting, it is important to distinguish between these two different types of submicroscopic branching channels in basaltic glass. In contrast to those attributed to microbial activity [7] (or alternatively, abiotic etch-tunnelling [8]), the branching channels (grooves) described here are only restricted to a $\sim 50 \mathrm{~nm}$ thick boundary layer of glass around the vesicles (i.e., are quasi-two-dimensional channels as opposed to 3dimensional tunnels), do not extend outwards into fresh glass, and were not produced by any kind of etching process (biotic [7] or abiotic [8]). In addition, they are not associated with palagonite alteration and are observed only within vesicles surrounded by fresh glass that were not intersected by fractures and exposed to seawater in their geological history.

\subsection{Implications for Experimental Studies of Viscous Fingering.}

Viscous fingering experiments in macroscopic Hele-Shaw cells are widely studied because of their broad physical applications including oil recovery, chemical processing, hydrology, and filtration [21]. Several features of the natural viscous fingers observed here make them a unique and rich source of information for understanding new problems in viscous fingering. Because they formed at the glass transition in a quenching pillow margin, they are the preserved relics of a presumably high-temperature $\left(\sim 600-700^{\circ} \mathrm{C}\right)$ viscous fingering event. The extraordinarily small (nanoscopic) size of these viscous fingers is probably a reflection of the very high viscosity ratio $\left(\sim 10^{15}\right)$ of the system and the small thickness $(\sim 50 \mathrm{~nm})$ of the boundary layer (natural Hele-Shaw cell), and both of these features represent new extremes in viscous fingering. Macroscopic viscous fingering experiments are classically studied in Hele-Shaw cells with relatively simple, flat geometries [21]. In contrast, the nanoscopic viscous fingering described in this study occurred within a spheroidal shell around each vesicle. Because the seemingly imposed unidirectionality of subsidiary side-branching observed in this study (e.g., Figure 5) remains entirely unexplained, this needs to be explored with viscous fingering experiments in spheroidal Hele-Shaw cells, and at high-temperature and high-viscosity ratio (e.g., with vapour/magmatic systems).
Viscous fingering trees identified in this study are notably complex skeletal structures with thin straight branches that are similar in appearance to experimental and simulated dendritic viscous fingers formed at high-viscosity ratio (e.g., $10^{4}$ ) [34]. In the natural system studied here, the viscosity ratio was $\sim 10^{15}$, which by analogy may have been an important factor in controlling the complexity and form of these skeletal viscous fingers. The complexity of dendritic viscous fingering patterns also increases with increasing flow rate [35], when driving relatively low-viscosity Newtonian fluids into complex non-Newtonian fluids such as polymeric liquids and liquid crystals $[36,37]$, and by narrowing the gap between plates in the Hele-Shaw cell [36]. These observations may be particularly relevant to the present study because basaltic melts exhibit non-Newtonian behaviour at high strain rates [38], and the gap width of the boundary layer (Hele-Shaw cell) is only $\sim 50 \mathrm{~nm}$.

4.3. Implications for Nanotechnology. Previously emplaced sulfide spherules embedded in the vesicle wall also had a very strong influence on pattern formation, acting as island walls to the Hele-Shaw cell (i.e., dehydrating boundary layer). Considered in combination with the regularity (predictability) of the viscous fingering patterns and the very small $(50-75 \mathrm{~nm})$ widths and depths $(\sim 50 \mathrm{~nm})$ of resultant nanogrooves, this observation is interesting from the standpoint of exploring new applications in the field of nanotechnology. One problem associated with the fabrication of grooved nanodevices using conventional techniques, including soft X-ray, extreme-UV lithography, and electron beam lithography, is the generation of complex patterns [10]. Logical placement of obstacles that impede nanoscopic viscous fingers of vapour in hot glass could potentially be used to produce patterns of selfassembling branching grooves that compete with stateof-the-art nanolithography techniques, both in terms of pattern complexity and size. In addition, the practical limit of nanolithography is around $20 \mathrm{~nm}$ [10], which is near in width to the dendritic nanogrooves in this study.

The generation of precise patterns and linear arrays of nanogrooves in materials has a number of uses that range from the stretching, aligning, and movement of DNA molecules $[39,40]$ to the fabrication of nanoelectronic devices and integrated circuits [10]. As the feature size in nanoelectronic devices continues to shrink (with $32 \mathrm{~nm}$ chips predicted for 2009) and nanolithography techniques reach their practical size limit of $\sim 20 \mathrm{~nm}$, alternatives to such variants of optical lithography techniques are currently being sought in the fabrication of nanointegrated circuits $[10,41]$. It was noted by Smith [10] that, likely, new alternatives to nanolithography will employ mechanisms of self-assembly such as the myriad forms of selfassembly exhibited by living systems. Here we propose that self-assembling dendritic patterns of nanogrooves formed by viscous fingering of vapour and silicate glass within nanoscopic ( $<50 \mathrm{~nm}$ thick) Hele-Shaw cells that have imaginary bounding plates, that is, ultra-thin film surface 
layer viscous fingering, could provide an important new alternative to nanolithography useful in the fabrication of nanoelectronic devices and integrated circuits. Several observations from the present study on natural glass support this claim.

Aside from the observed small width $(\sim 50-75 \mathrm{~nm})$, depth $(<50 \mathrm{~nm})$ and complex branching form of these grooves (e.g., Figure 5), which are desirable features in modern day nanolithography, there are other advantages that potentially make this a promising technique that will be useful in fabricating integrated circuits. First is their occurrence in silicate glass. $\mathrm{SiO}_{2}$ glass is the ideal dielectric material used in integrated circuits [42], and it may be used in passivation (protective coating) and diffusant masking [43], as gate dielectrics in Metal-Oxide-Semiconductor Field-Effect Transistors (MOSFETs) [43], or used as an insulating substrate onto which nanowire networks are formed in various nanodevices such as molecular random access memory cells (nanoCells) [44] and nanowire fieldeffect transistors [45]. This is partly for its physical properties including stability at temperatures over $900^{\circ} \mathrm{C}$, ability to be selectively removed from underlying silicon by etching, provides a barrier against chemical diffusion, and for its dielectric breakdown strength and good insulating properties [46]. But its widespread use is also because of the simplicity of growing $\mathrm{SiO}_{2}$ glass on silicon substrates-silicon being the most commonly used semiconductor material in integrated circuits $[42,43]$.

In fabricating integrated circuits, the formation of a thin layer of silica glass onto the silicon substrate is most commonly done by high-temperature $\left(900-1100^{\circ} \mathrm{C}\right)$ oxidation in either a wet or dry atmosphere containing water vapour, or oxygen, respectively [46]. In MOSFETs, gate oxides are only a few hundred angstroms thick or less $[43,46]$, and by comparison the dehydrated boundary layers described in this study range downward in thickness from $\sim 500 \AA$ (Figures 2(c) and 2(d)). Forming a very thin oxide layer in gate oxides during fabrication of MOSFETs means that dielectric breakdown may occur at quite a low voltage and that a fundamental lower limit exists for oxide thicknessfor instance, a $500 \AA$ thick layer would result in breakdown around $30 \mathrm{~V}$ [43]. Since the 1990s, MOSFETs have become nanodevices because the thickness of the $\mathrm{SiO}_{2}$ gate dielectric is about $3 \mathrm{~nm}$ for logics and $5 \mathrm{~nm}$ for nonvolatile memories [46]. However, because it is horizontal sizes that limit the IC integration, the development of a new nanodevice proper presently requires that at least one of its horizontal dimensions is between 1 and $100 \mathrm{~nm}$ in size [46]. This is the case for the nanogrooves identified in this study, because they are $\sim 50-75 \mathrm{~nm}$ wide, they have a branch spacing on the order of $\sim 100 \mathrm{~nm}$, and many of the individual branches are less than $100 \mathrm{~nm}$ long (Figure 1(c)).

Optical projection lithography has long been used in the planar fabrication process used in manufacturing integrated circuits, employing resists, patterned masks, and etching $[10,46]$. The process of generating windows and grooved patterns in thin $\mathrm{SiO}_{2}$ glass layers by this method, which exposes the underlying silicon for contact with aluminum in precise patterns that correspond to specific design portions of the integrated circuit, involves multiple steps [43]. First, a thin layer of $\mathrm{SiO}_{2}$ glass is grown on the silicon substrate (Figure 8(a)). The $\mathrm{SiO}_{2}$ layer is then coated with a radiation sensitive photoresist (Figure 8(b)) and a glass mask placed on top of this (Figure 8(c)), which is patterned with transparent and opaque areas that define a specific structural portion of the integrated circuit [43]. The wafer-mask system is then exposed to ultraviolet light, which hardens the negative-working photoresist where it is exposed, leaving the unexposed regions to be washed away during subsequent development and rinsing of the photoresist (Figure 8(d)) [43]. Immersing the wafer in hydrofluoric acid then etches away the regions of $\mathrm{SiO}_{2}$ glass not covered by the remaining photoresist (Figure $8(\mathrm{e})$ ), opening up precisely designed windows through the $\mathrm{SiO}_{2}$ layer and exposing the underlying silicon in the desired pattern, leaving it relatively unaffected by etching [43]. Removal of the remaining photoresist leaves the final patterned $\mathrm{SiO}_{2}$ glass layer on a silicon substrate (Figure 8(f)) [43].

Nanoscopic grooves in the natural glass in the present study are formed in a substrate that is not pure $\mathrm{SiO}_{2}$ glass, but rather, basaltic glass comprised of $\sim 51 \% \mathrm{SiO}_{2}$ in addition to numerous other oxides including $\sim 14 \% \mathrm{Al}_{2} \mathrm{O}_{3}, \sim 12 \%$ $\mathrm{CaO}, \sim 11 \%$ total Fe-oxide, $\sim 7 \% \mathrm{MgO}, \sim 2 \% \mathrm{Na}_{2} \mathrm{O}, \sim 1.5 \%$ $\mathrm{TiO}_{2}$, and other trace elements (data for adjacent glassy pillow margins at DSDP 418A: [47]). However, if complex branching nanoscopic grooves can form by ultrathin film surface layer viscous fingering between magmatic fluid and basaltic glass (Figure 7), it might be replicated in the laboratory using $\mathrm{CO}_{2}$ (or other vapours) and pure $\mathrm{SiO}_{2}$ glass at temperatures near the glass transition (Figures $8(\mathrm{~g})-8(\mathrm{i}))$. In this manner, generating patterns of dendritic nanogrooves useful in the fabrication of nanodevices and integrated circuits could be carried out by replicating the natural process observed on vesicle walls (Figure 7) in the laboratory, but in a thin layer of silica on a silicon substrate instead (Figures $8(\mathrm{~g})-8(\mathrm{i})$ ).

If it is possible to replicate such dendritic nanogrooves formed by thin film surface viscous fingering in $\mathrm{SiO}_{2}$ glass on a silicon substrate, it should be a relatively simple matter to design the branching networks to specified shapes. This could be done by controlling patterns of viscous finger propagation with obstacles placed at logical points in the layer. As they grew, nanoscopic viscous fingers observed in natural glass from this study were terminated (shielded) by two contrasting types of obstacles, including positive features (sulfide grains embedded in the glass) and negative features (other neighbouring viscous fingers). In considering a thin layer of $\mathrm{SiO}_{2}$ glass on silicon to represent a Hele-Shaw cell with imaginary bounding plates (i.e., the upper and lower surfaces of the $\mathrm{SiO}_{2}$ layer), then in the lateral dimensions obstacles that could be used to shield/deflect propagating viscous fingers in certain ways could be emplaced either by embedding/growing minerals in the $\mathrm{SiO}_{2}$ layer (positive features) or by making holes or lines (negative features) using electron beam lithography [48] or other nanolithography techniques.

There are also numerous morphological aspects of the natural grooves identified in this study that make them 
Traditional optical projection lithography (modified from [43]-Till and Luxon, 1982)

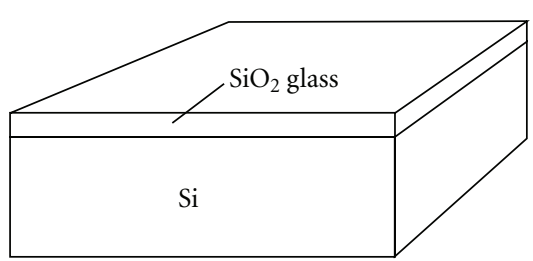

(a)

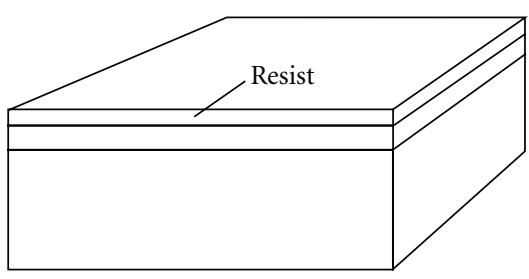

(c)

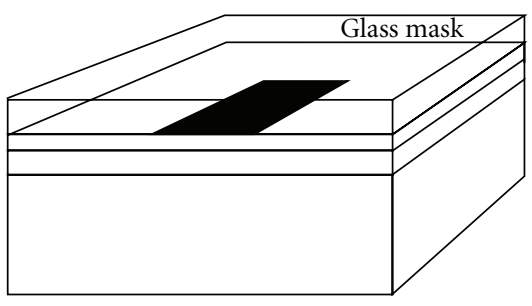

(e)

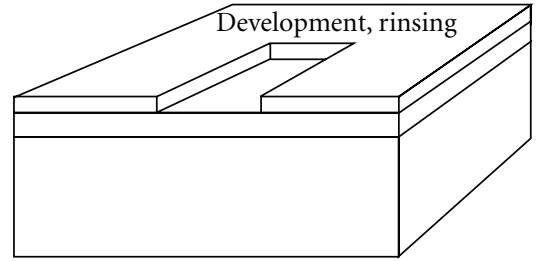

(b)

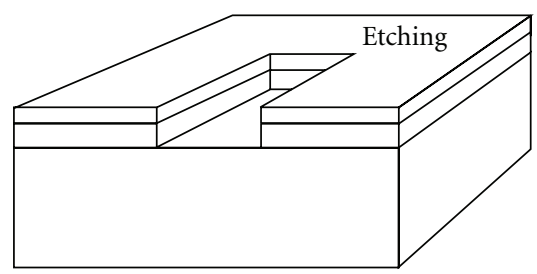

(d)

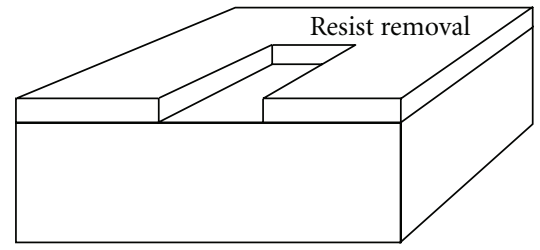

(f)

Proposed method of self assembling nanolithography based on high viscosity contrast fluid mechanical grooving at glass transition temperatures

(h)

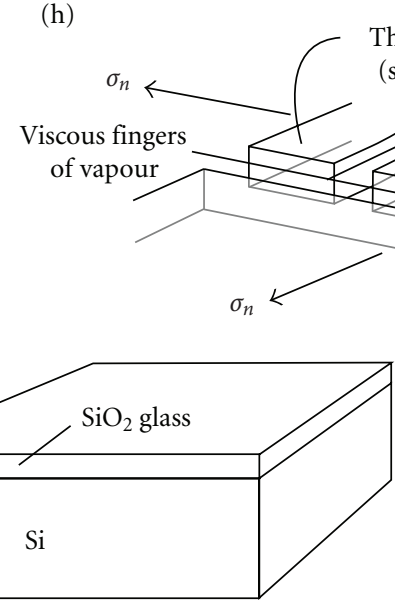

(g)
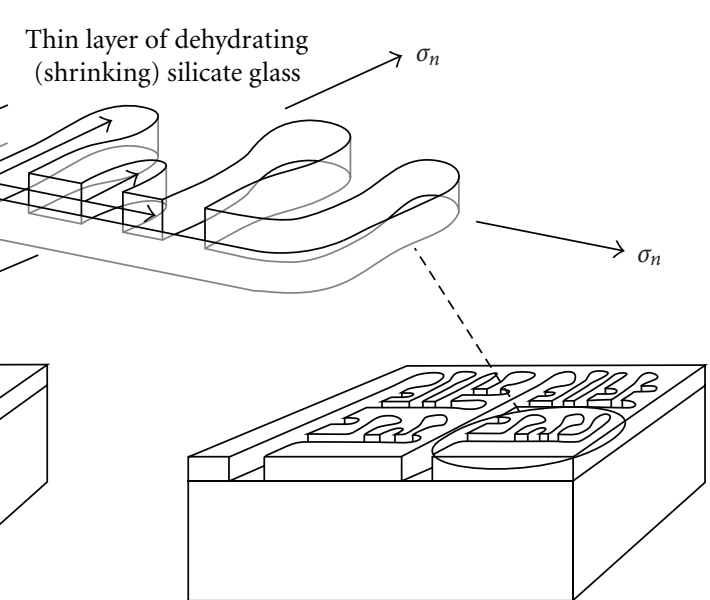

(i)

Figure 8: A comparison of traditional optical lithography techniques (a)-(f) used in the fabrication of integrated circuits [43] to a proposed new method of nanolithography based on high-viscosity contrast fluid mechanical grooving at glass transition temperatures in the $\mathrm{SiO}_{2}$ layer (g)-(i). 
interesting from the standpoint of designing nanointegrated circuits. For instance, semiconducting nanowires in field-effect transistors and single-electron transistors are typically $10-100 \mathrm{~nm}$ in diameter [41]. Although vertical arrays of nanowires may be grown by the vapour-liquidsolid approach, the extreme difficulty of gating and circuit wiring calls for development of new methods to grow horizontal arrays of branching nanowire networks [49]. Growth of hexagonal GaAs nanowire networks has already been used to fabricate horizontal branching linear nanowire arrays to a high node density $\left(10^{6}\right.$ to $\left.10^{8} \mathrm{~cm}^{-2}\right)$, which have applications in binary decision diagram logic architecture $[49,50]$. Dendritic nanowire networks potentially have a range of applications in nanoelectronics and integrated circuits, for example, in tree structured resistorcapacitor (RC) networks used in RC delays and matched $\mathrm{RC}$ trees (e.g.,: H-tree networks) that are employed in building clocks [42]. Development of such small-scale dendritic nanowire networks could be facilitated by the fluid mechanic-based, self-assembling mechanism of nanogrooving outlined in this study (Figures $8(\mathrm{~g})-8(\mathrm{i})$ ), especially because the observed node density is exceptionally high $\left(\sim 10^{10} \mathrm{~cm}^{-2}\right)$ in these natural examples of grooved patterns (e.g., Figure 1(b)).

\section{Summary and Conclusions}

We have determined the origin of dendritic patterns of nanoscopic grooves on vesicle walls, which occur globally in mid-ocean ridge basaltic glass. The $\sim 50-75 \mathrm{~nm}$ wide grooves form as the vapour within the vesicle undergoes viscous fingering with a thin $(\sim 50 \mathrm{~nm})$ shell of hot glass surrounding it, during quenching of the glassy pillow margin upon lava eruption. The pattern forming process is nearly identical to that observed in macroscopic viscous fingering experiments with Hele-Shaw cells and results in dendritic branching patterns of the same fractal dimension (1.38), despite being six orders of magnitude smaller. This viscous deformation is linked to numerical predictions of elastic shrinkage and radial microfracturing around some vesicle walls in glassy rocks, which happens upon cooling through the glass transition [6]. Because it occurred at extraordinarily highviscosity ratio $\left(\sim 10^{15}\right)$ in an exceptionally thin $(\sim 50 \mathrm{~nm})$, spheroidal layer, resulting in very narrow $(50-75 \mathrm{~nm}$ wide) viscous fingers with preferred side-branch directions, we highlight a number of previously unrecognized extremes in viscous fingering.

Replicating such high-viscosity contrast fluid mechanical nanogrooving in silica glass could provide a new alternative to nanolithography that is based on self-assembly. This would provide a range of novel applications in the field of nanotechnology, particularly in the manufacturing of grooved nanodevices. For instance, if this type of ultrathin film surface layer viscous fingering is possible in $\mathrm{SiO}_{2}$ glass on a silicon substrate, it might be used as a new alternative to traditional lithography techniques used in the fabrication of nanointegrated circuits.

\section{Acknowledgments}

The authors would like to thank George Braybrook and Rajeev Nair from the Department of Earth and Atmospheric Sciences, University of Alberta, for assistance with scanning electron microscopy studies. In addition, they would also like to acknowledge two anonymous reviewers for their helpful comments and editorial suggestions that resulted in significant improvements to the final version of this paper.

\section{References}

[1] V. S. Kamenetsky,, P. Davidson, T. P. Mernagh, et al., "Fluid bubbles in melt inclusions and pillow-rim glasses: hightemperature precursors to hydrothermal fluids?" Chemical Geology, vol. 183, pp. 349-364, 2002.

[2] J. G. Moore and L. Calk, "Sulfide spherules in vesicles of dredged pillow basalt," American Mineralogist, vol. 56, pp. 476-488, 1971.

[3] E. A. Mathez and R. S. Yeats, "Magmatic sulfides in basalt glass from DSDP Hole 319A and Site 320, Nazca Plate," Initial Reports of the Deep Sea Drilling Project, U.S. Government Printing Office, Washington, DC, USA, 1976.

[4] J. G. Moore, J. N. Batchelder, and C. G. Cunningham, " $\mathrm{CO}_{2}-$ filled vesicles in mid-ocean basalt," Journal of Volcanology and Geothermal Research, vol. 2, no. 4, pp. 309-327, 1977.

[5] R. S. Yeats and E. A. Mathez, "Decorated vesicles in deep-sea basalt glass, eastern pacific," Journal of Geophysical Research, vol. 81, no. 23, pp. 4277-4284, 1976.

[6] J. E. Mungall, N. S. Bagdassarov, C. Romano, and D. B. Dingwell, "Numerical modelling of stress generation and microfracturing of vesicle walls in glassy rocks," Journal of Volcanology and Geothermal Research, vol. 73, no. 1-2, pp. 3346, 1996.

[7] H. Furnes, N. R. Banerjee, H. Staudigel, et al., "Comparing petrographic signatures of bioalteration in recent to Mesoarchean pillow lavas: tracing subsurface life in oceanic igneous rocks," Precambrian Research, vol. 158, no. 3-4, pp. 156-176, 2007.

[8] J. E. French, K. Muehlenbachs, D. F. Blake, and N. R. Banerjee, "Identification of alpha-recoil and fission track etch-tunnels in mid-ocean ridge basaltic glass: Theoretical modelling of natural porosity," submitted to Geochimica et Cosmochimica Acta.

[9] Y. Wada, "Possible application of micromachine technology for nanometer lithography," Microelectronics Journal, vol. 29, no. 9, pp. 601-611, 1998.

[10] H. I. Smith, "Low cost nanolithography with nanoaccuracy," Physica E, vol. 11, no. 2-3, pp. 104-109, 2001.

[11] Shipboard Scientific Parties, "Site 418," Initial Reports of the Deep Sea Drilling Project, U.S. Government Printing Office, Washington, DC, USA, 1980.

[12] A. Arnéodo, Y. Couder, G. Grasseau, V. Hakim, and M. Rabaud, "Uncovering the analytical Saffman-Taylor finger in unstable viscous fingering and diffusion-limited aggregation," Physical Review Letters, vol. 63, no. 9, pp. 984-987, 1989.

[13] E. Lajeunesse and Y. Couder, "On the tip-splitting instability of viscous fingers," Journal of Fluid Mechanics, vol. 419, pp. 125149, 2000.

[14] S. Liang, "Random-walk simulations of flow in Hele Shaw cells," Physical Review A, vol. 33, no. 4, pp. 2663-2674, 1986. 
[15] D. L. Turcotte, Fractals and Chaos in Geology and Geophysics, vol. 398, Cambridge University Press, Cambridge, UK, 2nd edition, 1997.

[16] D. L. Turcotte, "Fractals in petrology," Lithos, vol. 65, no. 3-4, pp. 261-271, 2002.

[17] T. A. Witten Jr. and L. M. Sander, "Diffusion-limited aggregation, a kinetic critical phenomenon," Physical Review Letters, vol. 47, no. 19, pp. 1400-1403, 1981.

[18] M. E. Glicksman and A. O. Lupulescu, "Dendritic crystal growth in pure materials," Journal of Crystal Growth, vol. 264, no. 4, pp. 541-549, 2004.

[19] D. L. Turcotte, J. D. Pelletier, and W. I. Newman, "Networks with side branching in biology," Journal of Theoretical Biology, vol. 193, no. 4, pp. 577-592, 1998.

[20] J. G. Masek and D. L. Turcotte, "A diffusion-limited aggregation model for the evolution of drainage networks," Earth and Planetary Science Letters, vol. 119, no. 3, pp. 379-386, 1993.

[21] G. M. Homsy, "Viscous fingering in porous media," Annual Review of Fluid Mechanics, vol. 19, pp. 271-311, 1987.

[22] D. Bensimon, L. P. Kadanoff, S. Liang, B. I. Shraiman, and C. Tang, "Viscous flows in two dimensions," Reviews of Modern Physics, vol. 58, no. 4, pp. 977-999, 1986.

[23] P. G. Saffman, "Viscous fingering in Hele-Shaw cells," Journal of Fluid Mechanics, vol. 173, pp. 73-94, 1986.

[24] A. R. Kopf-Sill and G. M. Homsy, "Nonlinear unstable viscous fingers in Hele-Shaw flows," Physics of Fluids, vol. 31, pp. 242249, 1988.

[25] J. Nittmann, G. Daccord, and H. E. Stanley, "Fractal growth viscous fingers: quantitative characterization of a fluid instability phenomenon," Nature, vol. 314, pp. 141-144, 1985.

[26] R. J. Twiss and E. M. Moores, Structural Geology, vol. 532, W.H. Freeman, New York, NY, USA, 1992.

[27] D. Auerbach and G. Strobel, "Fingering patterns and their fractal dimensions," Chaos, Solitons \& Fractals, vol. 5, no. 10, pp. 1765-1773, 1995.

[28] A. Fenghour, W. A. Wakeham, and V. Vesovic, "The viscosity of carbon dioxide," Journal of Physical and Chemical Reference Data, vol. 27, no. 1, pp. 31-44, 1998.

[29] J. Gottsmann, A. J. L. Harris, and D. B. Dingwell, "Thermal history of Hawaiian pāhoehoe lava crusts at the glass transition: implications for flow rheology and emplacement," Earth and Planetary Science Letters, vol. 228, no. 3-4, pp. 343-353, 2004.

[30] J. G. Moore, "Vesicularity and $\mathrm{CO}_{2}$ in mid-ocean ridge basalt," Nature, vol. 282, no. 5736, pp. 250-253, 1979.

[31] P. Burnard, "The bubble-by-bubble volatile evolution of two mid-ocean ridge basalts," Earth and Planetary Science Letters, vol. 174, no. 1-2, pp. 199-211, 1999.

[32] E. Lemaire, P. Levitz, G. Daccord, and H. Van Damme, "From viscous fingering to viscoelastic fracturing in colloidal fluids," Physical Review Letters, vol. 67, no. 15, pp. 2009-2012, 1991.

[33] M. Javoy and F. Pineau, "The volatiles record of a "popping" rock from the Mid-Atlantic Ridge at $14^{\circ} \mathrm{N}$ : chemical and isotopic composition of gas trapped in the vesicles," Earth and Planetary Science Letters, vol. 107, no. 3-4, pp. 598-611, 1991.

[34] J.-H. Zhang and Z.-H. Liu, "Study of the relationship between fractal dimension and viscosity ratio for viscous fingering with a modified DLA model," Journal of Petroleum Science and Engineering, vol. 21, no. 1-2, pp. 123-128, 1998.

[35] A. Buka, J. Kertész, and T. Vicsek, "Transitions of viscous fingering patterns in nematic liquid crystals," Nature, vol. 323, no. 6087 , pp. $424-425,1986$.
[36] P. Fast, L. Kondic, M. J. Shelley, and P. Palffy-Muhoray, "Pattern formation in non-Newtonian Hele-Shaw flow," Physics of Fluids, vol. 13, no. 5, pp. 1191-1212, 2001.

[37] A. Lindner, D. Bonn, E. C. Poiré, M. B. Amar, and J. Meunier, "Viscous fingering in non-Newtonian fluids," Journal of Fluid Mechanics, vol. 469, pp. 237-256, 2002.

[38] S. L. Webb and D. B. Dingwell, "Non-Newtonian rheology of igneous melts at high stresses and strain rates: experimental results for rhyolite, andesite, basalt, and nephelinite," Journal of Geophysical Research, vol. 95, no. B10, pp. 15,695-15,701, 1990.

[39] D. Nyamjav and A. Ivanisevic, "Templates for DNA-templated $\mathrm{Fe}_{3} \mathrm{O}_{4}$ nanoparticles," Biomaterials, vol. 26, no. 15, pp. 27492757, 2005.

[40] K. Wang, S. Yue, L. Wang, et al., "Nanofluidic channels fabrication and manipulation of DNA molecules," IEE Proceedings Nanobiotechnology, vol. 153, no. 1, pp. 11-15, 2006.

[41] G. W. Hanson, Fundamentals of Nanoelectronics, vol. 385, Pearson Prentice Hall, Upper Saddle River, NJ, USA, 2008.

[42] J. Rabaey, A. Chandrakasan, and B. Nikolić, Digital Integrated Circuits: A Design Perspective, vol. 761, Pearson Education, Upper Saddle River, NJ, USA, 2nd edition, 2003.

[43] W. C. Till and J. T. Luxon, Integrated Circuits: Materials, Devices, and Fabrication, vol. 462, Prentice-Hall, Englewood Cliffs, NJ, USA, 1982.

[44] Y. Ma and J. M. Seminario, "Analysis of programmable molecular electronic systems," in Molecular and Nano Electronics: Analysis, Design and Simulation, J. M. Seminario, Ed., pp. 96140, Elsevier, Milan, Italy, 2007.

[45] Y. Huang, X. Duan, Y. Cui, and C. M. Lieber, "Gallium nitride nanowire nanodevices," Nano Letters, vol. 2, no. 2, pp. 101104, 2002.

[46] G. F. Cerofolini and D. Mascolo, "A hybrid route from CMOS to nano and molecular electronics," in Nanotechnology for Electronic Materials and Devices, A. Korkin, J. Labanowski, E. Gusev, and S. Luryi, Eds., pp. 1-65, Springer, New York, NY, USA, 2006.

[47] G. R. Byerly and J. M. Sinton, "Compositional trends in natural basaltic glasses from Deep Sea Drilling Project Holes 417D and 418A," Initial Report Deep Sea Drilling Project, U.S. Government Printing Office, Washington, DC, USA, 1980.

[48] C. Vieu, F. Carcenac, A. Pépin, et al., "Electron beam lithography: resolution limits and applications," Applied Surface Science, vol. 164, no. 1-4, pp. 111-117, 2000.

[49] I. Tamai and H. Hasegawa, "Selective MBE growth of hexagonal networks of trapezoidal and triangular GaAs nanowires on patterned (111)B substrates," Journal of Crystal Growth, vol. 301-302, pp. 857-861, 2007.

[50] S. Kasai and H. Hasegawa, "GaAs and InGaAs single electron hexagonal nanowire circuits based on binary decision diagram logic architecture," Physica E, vol. 13, no. 2-4, pp. 925-929, 2002. 

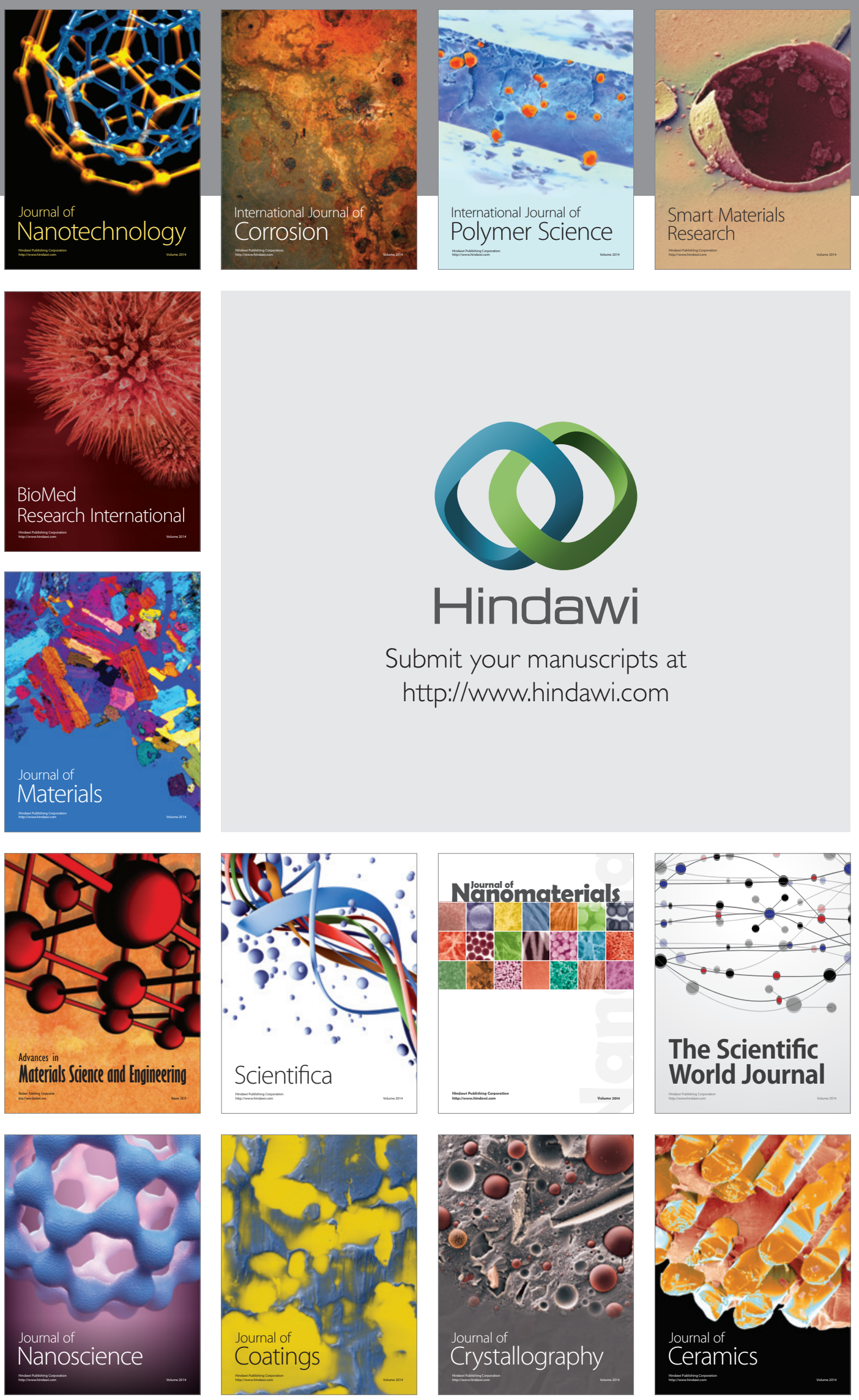

The Scientific World Journal

Submit your manuscripts at

http://www.hindawi.com

\section{World Journal}

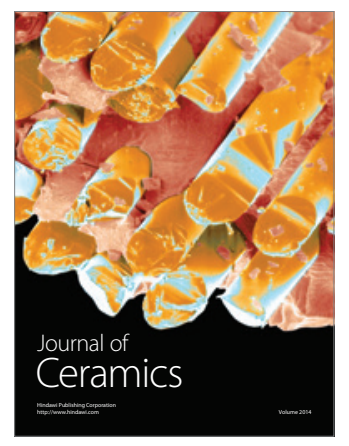

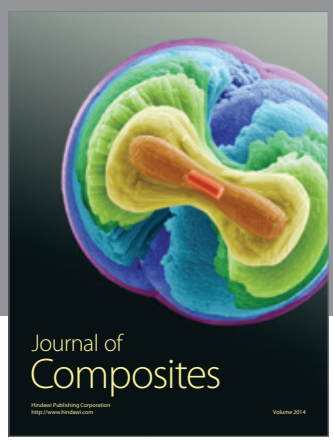
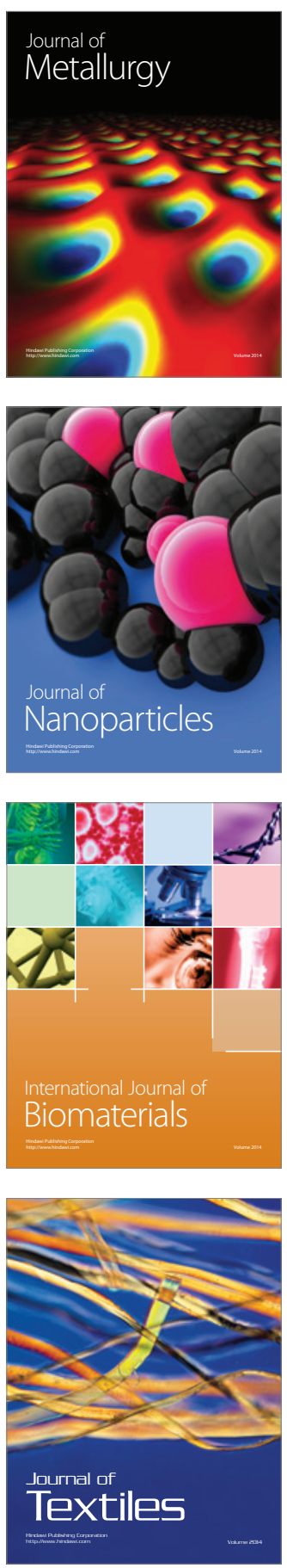